\title{
LATIHAN AEROBIK YANG AMAN BAGI PENDERITA HIPERTENSI
}

Oleh: Cerika Rismayanthi

Dosen Jurusan Pendidikan Kesehatan dan Rekreasi FIK UNY

\section{Abstrak}

Hipertensi adalah desakan darah yang berlebihan dan hampir konsen terhadap arteri. Tekanan dihasilkan oleh kekuatan jantung ketika memompa darah. Tekanan darah tinggi dapat ditentukan oleh adanya kenaikan darah sistolik atau diastolik. Tekanan darah sistolik yang normal rata-rata $120 \mathrm{~mm} \mathrm{Hg}$ dan diastolik ratarata $80 \mathrm{~mm} \mathrm{Hg}$ dengan variasi yang tertinggi yang masih dapat dikatakan normal untuk sistolik sebesar 130-140 mm Hg dan untuk diastolik sampai $90 \mathrm{~mm} \mathrm{Hg}$.

Jenis olahraga yang efektif menurunkan tekanan darah adalah olahraga aerobik dengan intensitas sedang yang bersifat intermiten, yaitu dengan durasi 1 menit untuk antensitas sedikit lebih tinggi atau sampai penderita merasa rerengah-engah, dan yang 3 menit untuk istirahat aktif. Salah satu contohnya, jalan kaki cepat. Frekuensi latihannya 2 sampai 3 kali seminggu, dengan lama latihan 20 - 60 menit sekali latihan. Namun dalam makalah ini, jenis olahraga yaitu dengan menggunakan senam aerobik yang dapat dilakukan dipusat kebugaran atau dirumah.

MEDIKORA Vol. IV, No 1, April 2008: 83-102 
Olahraga ini adalah salah satu cara untuk mendapatkan hasil terbaru untuk menurunkan tekanan darah tinggi atau hipertensi.

Latihan aerobik dapat menurunkan tekanan darah karena latihan itu dapat merilekskan pembuluh-pembuluh darah. Lama-kelamaan, latihan olahraga dapat melemaskan pembuluhpembuluh darah, sehingga tekanan darah menurun, sama halnya dengan melebarnya pipa air akan menurunkan tekanan air. Latihan olahraga juga dapat menyebabkan aktivitas saraf, reseptor hormon, dan produksi hormon-hormon tertentu menurun. Bagi penderita hipertensi latihan aerobik dengan intensitas ringan dan bersifat intermitten tetap cukup aman dilakukan setiap saat.

Kata kunci: latihan aerobik, hipertensi

Seperti air yang mengalir didalam selang begitu pula darah manusia, darah dipompa dari jantung dan mengalir melalui pembuluh darah mulai dari yang berdiameter besar sampai yang berdiameter kecil menuju ke setiap organ tubuh. Darah mengalir ditentukan oleh kuatnya pompaan jantung dan besarnya tekanan dalam pembuluh darah. Pada saat jantung memompakan darah akan timbul tekanan pada dinding pembuluh darah yang disebut tekanan sistolik, sedangkan pada saat jantung selesai memompa darah jantung akan membuka katupnya dan darah akan mengisi ruang jantung, nah pada saat inilah pembuluh darah mengatur tekanannya 
sehingga tetap ada darah yang mengalir pada saat sebagian darah mengisi pompa jantung, tekanan pada saat ini disebut tekanan diastolik.

Normalnya tekanan sistolik berkisar antara 100-120 mmHg dan tekanan diastolik 60-80mmHg. Pada suatu keadaan tekanan darah dapat saja meninggi, apabila hal ini terjadi terus menerus dalam jangka waktu lama dengan tekanan darah sistolik $\geq 140 \mathrm{mmHg}$ dan tekanan diastolik $\geq$ $90 \mathrm{mmHg}$ hal ini disebut dengan Tekanan Darah Tinggi atau hipertensi. Latihan aerobik memang dapat menurunkan tekanan darah sewaktu istirahat. Akan tetapi dalam penelitian kami tersebut di atas, latihan aerobic dilakukan bersama-sama dengan pengobatan hipertensi. Latihan aerobik bukan merupakan pengobatan untuk hipertensi, akan tetapi dapat dipergunakan sebagai terapi tambahan untuk penderita-penderita hipertensi. Penderita hipertensi jangan heran bila kebutuhan akan obat hipertensi menurun dalam pengobatan teratur dengan latihan aerobik. Atas dasar yang sama, hiperkholesterolemia tidak dapat diatasi dengan latihan aerobic saja. Akan tetapi bersama-sama dengan perobahan susunan makanan, latihan aerobik akan menurunkan kadar kholesterol darah. Latihan olahraga juga dapat menyebabkan aktivitas saraf, reseptor hormon, dan

MEDIKORA Vol. IV, No 1, April 2008: 83-102 
produksi hormon-hormon tertentu menurun. Bagi penderita hipertensi latihan olahraga tetap cukup aman.

Tekanan darah pada orang dewasa yang tergolong normal berkisar antara 110 sampai $90 \mathrm{~mm} \mathrm{Hg}, 140 \mathrm{mmHg}$ sistolik dan 70 sampai $90 \mathrm{mmHg}$ diastolik. Tekanan darah biasanya ditulis sebagai rasio dari kedua tekanan tadi. Dengan melihat beberapa pengertian diatas dapat dikatakan seseorang menderita hipertensi apabila tekanan darahnya mencapai 140/90 mm Hg atau lebih. Menurut Jonathan Kuntaraf (1992: 60) pembagian hipertensi adalah sebagai berikut:

a. Hipertensi berat apabila tekanan darah 180/115 mm Hg ke atas.

b. Hipertensi sedang apabila tekanan darah $160 / 105 \mathrm{~mm} \mathrm{Hg}$ sampai 180/115 mm Hg.

c. Hipertensi ringan apabila tekanan darah 160/105 mm Hg sampai 160/105 mm Hg.

Sedangkan pembagian hipertensi berdasarkan tingkat tekanan diastolik menurut Timothy (1985:8) adalah:

a. Mild Hypertension (hipertensi ringan) apabila tekanan diastolik 90-104 mm Hg. 
b. Moderate Hypertension (hipertensi sedang) apabila tekanan diastolik 105-114 mm Hg.

c. Severe Hypertension (hipertensi berat) apabila tekanan diastolik lebih dari $115 \mathrm{~mm} \mathrm{Hg}$.

Tekanan darah tinggi atau hipertensi merupakan satu diantara sekian banyak penyebab gangguan pada jantung dan pembuluh darah. Hipertensi seringkali tidak memberikan tanda-tanda peringatan kepada kita sehingga bisa menjadi pembunuh diam-diam (silent killer), kecuali jika kita secara tetap tentu melakukan pemeriksaan dan pengobatan ke dokter. Karena itu kepada setiap orang dewasa dianjurkan untuk mengetahui tekanan darahnya sendiri, karena ini menyangkut kesehatannya sendiri.

\section{Pengertian Senam Aerobik}

Latihan senam aerobik merupakan latihan yang menggerakkan seluruh otot terutama otot besar dengan gerakan yang mantap, terus-menerus, berirama, maju dan berkelanjutan. Dalam senam aerobik bisa dipilih gerakan yang mudah, menyenagkan dan bervariasi sehingga memungkinkan seseorang untuk melakukannya secara teratur dalam kurun waktu yang lama. Pada latihan ini, daya tahan jantung dan paru-paru merupakan sasaran utama,

MEDIKORA Vol. IV, No 1, April 2008: 83-102 
disamping sasaran-sasaran yang lain yang mendukung peningkatan tingkat kebugaran seseorang. (Woerjati Soekarno', 1996: 1).

Akhir-akhir ini senam aerobik sudah menjadi sangat populer tidak hanya bagi kaum wanita saja tetapi juga bagi kaum pria baik tua maupun muda. Mereka sama-sama melakukan senam arobik demi kesegaran dan kegembiraannya. Terlebih senam aerobik dapat diiringi oleh suara musik sesuai dengan kesenangannya dan iramanya menjadi panduan dari gerakan yang dilakukannya, hal ini menambah suasana menarik dan menyenagkan. Banyak sanggar senam dan fitness centre membentuk kelas-kelas untuk senam aerobik. Dalam kelas-kelas itu, diajarkan atau diberikan senam aerobik dengan high impact (benturan keras), low impact (benturan ringan), multi impact/ medium impact (gabungan antara high impact dan low impact).

Latihan aerobik yang dilakukan agar dapat berpengaruh terhadap efisiensi kerja jantung, sebaiknya latihan berada pada intensitas sedang yaitu denyut jantung 150-170 per menit. Intensitas sedang kurang lebih sama dengan 70-80\% dari kapasitas aerobik maksimal (Bompa, 1994 78). Jenis olahraga yang efektif menurunkan tekanan darah adalah olahraga aerobik dengan intensitas sedang. 
Salah satu contohnya, jalan kaki cepat, senam aerobik, dan yang lainnya. Frekuensi latihannya 3-5 kali seminggu, dengan lama latihan 20-60 menit sekali latihan. Latihan aerobik dapat menurunkan tekanan darah karena latihan itu dapat merilekskan pembuluh-pembuluh darah. Lama-kelamaan, latihan olahraga dapat melemaskan pembuluh-pembuluh darah, sehingga tekanan darah menurun, sama halnya dengan melebarnya pipa air akan menurunkan tekanan air.

\section{Prinsip dan Aturan Senam Aerobik}

Berkaitan dengan prinsip dan aturan senam aerobik ada beberapa hal yangperlu di perhatikan dalam melaksanakan senam aerobik. Beberapa hal yang perlu/harus di perhatikan adalah sebagai berikut:

1. Jenis, macam latihan yang harus diseleksi dan diteliti (setelah melalui analisa yang cermat tentang pengaruhnya terhadap tubuh). Latihan yang tidak berguna/tidak bermanfaat harus dihilangkan.

2. Pelaksanaan gerak harus tepat, untuk itu perlu adanya koreksi dan remidi

3. Gerakan dilakukan dengan sikap permulaan dan akhira yang benar

MEDI KORA Vol. IV, No 1, April 2008: 83-102 
4. Semua latihan harus disesuaikan dengan dosis/takaran yang sesuai dengan tujuannya.

Latihan yang teratur dan terstruktur merupakan ciri latihan senam arobik yang diharapkan. Untuk meenuhi sasaran latihan yang baik dan benar perlu diperhatikan takaran yang tepat dalam melakukannya. Dibawah ini adalah contoh latihan senam aerobik yang bisa diterapkan pada saat latihan adalah sebagai berikut:

\section{Pemanasan dan Pendinginan:}

1. Tekuk kepala ke samping, lalu tahan dengan tangan pada sisi yang sama dengan arah kepala. Tahan dengan hitungan 8-10, lalu bergantian dengan sisi lain.

2. Tautkan jari-jari kedua tangan dan angkat lurus ke atas kepala dengan posisi kedua kaki dibuka selebar bahu. Tahan dengan 8-10 hitungan. Rasakan tarikan bahu dan punggung.

3. Kedua kaki dibuka selebar bahu, lingkarkan satu tangan ke leher dan tahan dengan tangan lainnya. Hitungan 8-10 kali dan lakukan pada sisi lainnya.

4. Posisi tetap, tautkan kedua tangan lalu gerakkan ke samping dengan gerakan setengah putaran. Tahan 8-10 kali hitungan lalu arahkan tangan ke sisi lainnya dan tahan dengan hitungan sama. 


\section{Contoh Gerakan Inti Low Impact.}

1. Lakukan gerakan seperti jalan di tempat dengan lambaian kedua tartgan searah dengan sisi kaki yang diangkat. Lakukan perlahan dan hindari hentakan.

2. Buka kedua tangan dengan jemari mengepal dan kaki dibuka selebar bahu. Kedua kepalan tangan bertemu, dan ulangi gerakan semampunya sambil mengatur napas.

3. Kedua kaki dibuka agak lebar lalu angkat tangan menyerong. Sisi kaki yang searah dengan tangan sedikit ditekut. Tangan diletakkan di pinggang dan kepala searah dengan gerakan tangan. Tahan 8-10 kali hitungan lalu ganti dengan sisi lainnya.

4. Gerakan hampir sama dengan sebelumnya, tapi jari mengepal dan kedua tangan diangkat ke atas. Lakukan bergantian secara perlahan dan semampunya.

5. Hampir sama dengan gerakan inti 1 , tapi kaki dibuang ke samping. Kedua tangan dengan jemari mengepal ke arah yang berlawanan. Ulangi dengan sisi bergantian.

6. Kedua kaki dibuka lebih lebar dari bahu, satu lutut agak ditekuk dan tangan yang searah lutut di pinggang. Tangan sisi yang lain lurus ke arah lutut yang ditekuk. Ulangi gerakan ke arah sebaliknya dan lakukan semampunya.

MEDIKORA Vol. IV, No 1, April 2008: 83-102 


\section{Latihan Aerobik Bagi Penderita Hipertensi}

Bagi penderita hipertensi faktor yang harus diperhatikan adalah tingginya tekanan darah. Semakin tinggi tekanan darah semakin keras kerja jantung, sebab untuk mengalirkan darah saat jantung memompa maka jantung harus mengeluarkan tenaga sesuai dengan tingginya tekanan tersebut. Jantung apabila tidak mampu memompa dengan tekanan setinggi itu, berarti jantung akan gagal memompa darah. Latihan olahraga dapat menurunkan tekanan sistolik maupun diastolik pada usia tengah baya yang sehat dan juga mereka yang mempunyai tekanan darah tinggi ringan. Latihan olahraga tidak secara signifikan menurunkan tensi pada penderita yang mengalami hipertensi berat, tetapi paling tidak olahraga membuat seseorang menjadi lebih santai.

Pada penderita hipertensi, faktor tekanan darah memegang peranan penting di dalam menentukan boleh tidaknya berolahraga, takaran dan jenis olahraga. Beberapa pedoman di bawah ini perlu dipenuhi sebelum memutuskan berolahraga, antara lain;

a. Penderita hipertensi dikontrol tanpa atau dengan obat terlebih dahulu tekanan darahnya, sehingga tekanan darah sistolik tidak melebihi $160 \mathrm{mmHg}$ dan tekanan diastolik tidak melebihi $100 \mathrm{mmHg}$. 
b. Sebelum berolahraga, perlu mendapatkan informasi mengenai penyebab hipertensinya. Selain itu, kondisi organ tubùh yang akan terpengaruh oleh penyakit tersebut seperti: keadaan jantung, keadaan ginjal, keadaan mata (untuk mengetahui derajat hipertensi), serta pemeriksaan laboratorium darah maupun urin. Kondisi organ tersebut akan mempengaruhi keberhasilan olahraga yang dilakukan.

c. Penderita hipertensi sebelum latihan, sebaiknya melakukan Uji Latih Jantung terlebih dahulu dengan beban (treadmill/ergometer) agar dapat dinilai reaksi tekanan darah dan perubahan aktifitas listrik jantung (EKG) serta menilai tingkat kapasitas fisik. Berdasarkan hasil Uji Latih Jantung, dosis latihan dapat diberikan secara akurat.

d. Pada saat Uji Latih sebaiknya obat yang sedang diminum tetap diteruskan, sehingga dapat diketahui efektifitas obat terhadap kenaikan beban. Obat yang diberikan apakah sudah tepat artinya tekanan darah berada dalam lingkup ukuran normal atau masih menunjukkan reaksi hipertensi ketika diberikan tes pembebanan. Dokter akan berusaha mengatur kembali dosis obat apabila belum tepat.

MEDIKORA Vol. IV, No 1, April 2008: 83-102 
e. Latihan yang dilakukan untuk meningkatkan daya tahan (endurance) dan tidak boleh menambah peningkatan tekanán (pressure). Olahraga yang tepat adalah jalan kaki, bersepeda, senam dan berenang atau olahraga aerobik.

f. Olahraga yang bersifat kompetisi tidak diperbolehkan. Olahraga yang bersifat akompetisi akan memacu emosi, sehingga mempercepat peningkatan tekanan darah.

g. Olahraga peningkatan kekuatan tidak diperbolehkan seperti angkat berat, karena menyebabkan peningkatan tekanan darah secara mendadak dan melonjak.

h. Tekanan darah secara teratur diperiksa sebelum dan sesudah latihan. Olahraga pada penderita hipertensi tidak hanya ditentukan oleh denyut jantung, tetapi juga berdasarkan reaksi tekanan darahnya.

i. Bagi penderita hipertensi ringan (tensi 160/95 mmHg tanpa obat), maka olahraga disertai pengaturan makan (mengurangi konsumsi garam) dan penurunan berat badan dapat menurunkan tekanan darah sampai tingkat normal 140/80 mmHg.

j. Penderita hipertensi umumnya berhubungan dengan beban emosi (stress). Oleh karena itu disamping olahraga yang bersifat fisik, olahraga pengendalian emosi seperti: 
meditasi, dzikir dan beribadah sesuai agama masingmasing sangat penting dilakukan.

k. Hasil latihan jika menunjukkan penurunan tekanan darah, maka dosis obat yang diberikan sebaiknya dikurangi (penyesuaian).

Olahraga dapat membantu menurunkan tekanan darah tinggi. Selain itu dapat membuat penampilan seseorang menjadi lebih muda, bugar, lebih fit dan fresh, serta dapat pula menaikkan kadar HDL (High Density Lipoprotein). Juga berperan pula dalam membantu menurunkan berat badan, meredam stress dan memperkecil resiko terserang penyakit jantung koroner (Arcole Margathan, 1995:93). Tekanan darah yang lebih rendah dijumpai pada individu yang fisiknya lebih sehat. Karena tekanandarah tinggi merupakan faktor resiko untuk timbulnya penyakit jantung, maka masukkan latihan fisik secara terratur dalam kegiatan sehari-hari adalah penting untuk mencegah hipertensi dan penyakit jantung (Alison Hull, 1993:30). Bryant Stamford, Ph.D. dalam penelitiannya mengungkapkan bahwa olahraga endurance, dapat menurunkan tekanan sistolik maupun diastolik pada orang yang mempunyai tekanan darah tinggi tingkat ringan. Olahraga aerobik menimbulkan efek seperti: beta blocker yang dapat menenangkan sistem saraf simpatikus dan 
melambatkan denyut jantung. Olahraga juga dapat menurunkan jumlah keluaran noradrenalin dan hormonhormon 'lain yang menyebabkan stres, yaitu yang menyebabkan pembuluh-pembuluh darah menciut dan menaikkan tekanan darah (Sadoso Sumosardjuno, 1995: 9394).

Contoh Gerakan Inti Medium Impact:

\begin{tabular}{|c|c|c|}
\hline $\begin{array}{c}\text { Hitunga } \\
\mathrm{n}\end{array}$ & Bagian bawah tubuh & Bagian atas tubuh \\
\hline $1-8$ & Grapevine $R$, Step touch $\times 2$ & $\begin{array}{l}\text { Menekan ke bawah x } \\
3 \text {, tepuk x } 2\end{array}$ \\
\hline $9-16$ & Grapevine L, step touch $\times 2$ & $\begin{array}{l}\text { Menekan ke bawah x } \\
3 \text {, tepuk x } 2\end{array}$ \\
\hline $17-24$ & Grapevine R, Step touch $\times 2$ & $\begin{array}{l}\text { Menekan ke bawah x } \\
3 \text {, tepuk x } 2\end{array}$ \\
\hline $25-32$ & Grapevine L, step touch $\times 2$ & $\begin{array}{l}\text { Menekan ke bawah x } \\
3 \text {, tepuk x } 2\end{array}$ \\
\hline $1-32$ & $\begin{array}{l}\text { Skip x 8, touch step ke } \\
\text { depan x } 4\end{array}$ & \begin{tabular}{|l} 
Menarik rendah ke \\
belakang $x$ 8
\end{tabular} \\
\hline $1-8$ & Menangkat lutut $(\mathrm{R}, \mathrm{L}, \mathrm{R})$ × 3 & Menekan dada x 3 \\
\hline $9-16$ & Berbaris $(R, L, R) \times 3$ & Meninju ke bawah x 3 \\
\hline $17-24$ & Menangkat lutut $(R, L, R) \times 3$ & Menekan dada x 3 \\
\hline
\end{tabular}




\begin{tabular}{|c|c|c|}
\hline Hitungan & Bagian bawah tubuh & Bagian atas tubuh \\
\hline $1-8$ & $\begin{array}{l}\text { Touch step ke samping } \\
\mathrm{x} 4\end{array}$ & $\begin{array}{l}\text { Mengangkat deltoid } \\
\text { kesamping x } 4\end{array}$ \\
\hline $9-16$ & Berjalan kedepan x 4 & Memompa x 4 \\
\hline $17-24$ & $\begin{array}{l}\text { Touch step ke samping } \\
\times 4\end{array}$ & $\begin{array}{l}\text { Mengangkat deltoid } \\
\text { kesamping } \times 4\end{array}$ \\
\hline $25-32$ & $\begin{array}{l}\text { Berjalan ke belakang } x \\
4\end{array}$ & Memompa x 4 \\
\hline $1-32$ & $\begin{array}{l}\text { Menendang rendah } \\
\text { kedepan dan belakang } \\
\text { secara bergantian } \times 4\end{array}$ & $\begin{array}{l}\text { Meninju keatas } \\
\text { kepala } \mathrm{x} 4\end{array}$ \\
\hline $\begin{array}{l}1-8 \\
9-16\end{array}$ & $\begin{array}{l}\text { Berjalan kedepan x } 4 \text {, } \\
\text { jejakkan }\end{array}$ & $\begin{array}{l}\text { Menekan kebawah } \mathrm{x} \\
4 \text { dan tepuk }\end{array}$ \\
\hline $17-24$ & $\begin{array}{l}\text { Berjalan kebelakang x } 4 \text {, } \\
\text { jejakkan }\end{array}$ & $\begin{array}{l}\text { Menekan kebawah } \mathrm{x} \\
4 \text { dan tepuk }\end{array}$ \\
\hline $25-32$ & $\begin{array}{l}\text { Step touch kedepan } \mathrm{x} \\
4\end{array}$ & $\begin{array}{l}\text { Menarik rendah ke } \\
\text { belakang x } 4\end{array}$ \\
\hline & $\begin{array}{l}\text { Step touch kebelakang } \\
\times 4\end{array}$ & $\begin{array}{l}\text { Menarik rendah ke } \\
\text { belakang x } 4\end{array}$ \\
\hline
\end{tabular}

MEDIKORA Vol. IV, No 1, April 2008: 83-102 


\begin{tabular}{|c|c|c|}
\hline Hitungan & Bagian bawah tubuh & Bagian atas tubuh \\
\hline $1-8$ & Berbaris kearah depan $\mathrm{x} 8$ & Memompa x 8 \\
\hline $9-16$ & Step Touch (OTS) x 4 & Bisep melingkar $\mathrm{x} 4$ \\
\hline $17-24$ & Berbaris ke belakang $x 8$ & Memompa $\times 8$ \\
\hline $25-32$ & Step Touch (OTS) x 4 & Bisep melingkar $\mathrm{x} 4$ \\
\hline $1-32$ & $\begin{array}{l}\text { Touch step (ke samping) } \mathrm{x} \\
16\end{array}$ & $\begin{array}{l}\text { Mengangkat deltoid } \\
\text { ke samping }\end{array}$ \\
\hline $1-8$ & & Triplet (ke arah $\mathrm{R}) \times 4$ \\
\hline $9-16$ & $\begin{array}{l}\text { Twist (kembali ke tengah) } \\
\mathrm{x} 8\end{array}$ & $\begin{array}{l}\text { Twist (kembali ke } \\
\text { tengah) } \times 8\end{array}$ \\
\hline $17-24$ & Triplet (ke arah R) x 4 & Triplet (ke arah $\mathrm{R})$ x 4 \\
\hline $25-32$ & $\begin{array}{l}\text { Twist (kembali ke tengah) } \\
\text { x } 8\end{array}$ & $\begin{array}{l}\text { Twist (kembali ke } \\
\text { tengah) } \times 8\end{array}$ \\
\hline
\end{tabular}

\section{KESIMPULAN}

Pengaruh pembuluh darah kapiler setelah melakukan olahraga adalah: kapiler-kapiler menjadi lebih padat pada orang yang berolahraga (terjadi neokapilarisasi), pasokan oksigen dan nutrisi menjadi lebih lancar, serta bantuan 
terhadap kerja vena karena adanya percepatan pengembalian darah kejantung.

Jenis olahraga yang efektif menurunkan tekanan darah adalah olahraga aerobik dengan intensitas sedang yang bersifat intermiten, yaitu dengan durasi 1 menit untuk antensitas sedikit lebih tinggi atau sampai penderita merasa rerengah-engah, dan yang 3 menit untuk istirahat aktif. Salah satu contohnya, jalan kaki cepat. Frekuensi latihannya 2-3 kali seminggu, dengan lama latihan 20-60 menit sekali latihan.

Efek olahraga terhadap pembuluh darah adalah: pembuluh darah akan melebar (vasodilatasi), saraf simpatis dan parasimpatis pembuluh darah akan didekatnya, panas tubuh akan melebarkan pembuluh darah, dan elasitisitas dinding pembuluh darah yang baik (khususnya pada olahraga yang berrsifat aerob) terjadi pada tubuh.kecepatan denyut jantung adalah salah satu faktor yang paling mudah dipantau yang memperlihatkan baik respon segera terhadap olahraga maupun adaptasi jangka panjang terhadap program olahraga tertentu. Sewaktu seseorang melakukan gerak badan (berolahraga) sel-sel otot yang aktif mengguanakan lebih banyak oksigen untuk menunjang peningkatan kebutuhan energi yang digunakan pada waktu berolahraga. Kecepatan

MEDIKORA Vol. IV, No 1, April 2008: 83-102 
denyut jantung meningkat untuk menyalurkan lebih banyak darah beroksigen keotot. Jantung beradaptasi terhadap olahraga teratur dengan intensitas dan durasi yang cukup, dengan meningkatkan kekuatas dan efesiensinya, sehingga jantung dapat memompa lebih banyak darah per denyutnya.

Setelah mengikuti latihan aerobik dengan intensitas yang sedang denyut nadi menjadi lebih rendah dan tekanan darah menjadi berkurang, minimal ada penurunan tekanan darah, meskipun belum maksimal. Diharapkan setelah mengikuti latihan aerobik ini, para penderita hipertensi dapat lebih mengurangi kenaikan tekanan darah, darah lebih dapat meminimalisir terjadinya serangan jantung dan hipertensi setiap harinya. Meskipun makalah ini belum sempurna, karena penulis tidak dapat mengetahui kebiasaan pola makan, kebiasaan hidup dan pengelolaan stress yang biasanya dialami oleh penderita.

\section{Daftar Pustaka}

Bompa TO. (1994). Theory and Methodologi of Training The Key to Athletic Performance. 2nd Edition, Lowa:Kendall/Hunt Publishing Company.

Dede Kusmana. (2002). Olahraga bagi Kesehatan Jantung, Jakarta: Fakultas Kedokteran Universitas Indonesia. 
Dede Kusmana. (2006). Olahraga Untuk Orang Sehat dan Penderita Penyakit Jantung. Jakarta: Balai Penerbit Fakultas Kedokteran Universitas Indonesia. Guidlines Subcommittee: 1999 World Health Organization International Society of Hypertension Guidlines for Management of Hypertension 1999, 17: 151-183.

WHO-ISH (2005). Hypertension. Diambil pada tanggal 20 November 2008 dari http/ / www.omron.com.

Jonathan Kuntaraf (1992). Olahraga Sumber Kesehatan. Bandung: Percetakan Advent.

Lany Gunawan (2001), Hipertensi (Tekanan Darah Tinggi), Cetakan V, Yogyakarta: Kanisius

Made Astawan. (11 juni 2007). Cegah Hipertensi dengan Pola Makan. Diambil pada tanggal 18 Agustus 2008 dari http//depkes.go.id/index.php? viearticle\&artid.

Nany Selamiharja. Hipertensi Terkendali, Stroke tak terjadi. Diambil pada tanggal 2 September 2008 dari http//indomedia.com/intisari/1999/september/hiper htm.

Niniek Soetini. (2007). Meningkatkan Stamina Penderita Hipertensi. Diambil pada tanggal 11 Juni 2008 dari http//surya.co.id/web/index2.php? content\&do_pdf. option $=$ com $_{-}$ 
Sadoso Sumosardjuno. (1995). Pengetahuan Praktis Kesehatan dalam Olahraga 3. Jakarta: PT Gramedia Puștaka Utama.

Sidabutar, RP \& Wiguno P: Hipertensi Essensial, Didalam: Ilmu Penyakit Dalam, Balai Penerbit FKUI 1990: Jilid II; 2005-223

Soekarno W, (1985). Teori \& Praktek Senam Dasar, Klaten: Pt.Intan Pariwara.

Vitahealth. (2006). Hipertensi, Jakarta: PT Gramedia Pustaka Utama. 